\title{
ESTIRPES DE Staphylococcus aureus ISOLADAS DE QUEIJO MINAS ARTESANAL DE ARAXÁ
}

\author{
STRAINS OF Staphylococcus aureus ISOLATED FROM MINAS ARTISANAL CHEESE \\ FROM ARAXÁ
}

\author{
V. SOUZA ${ }^{1}$, P. C. MELO ${ }^{2}$, M. I. M. MEDEIROS ${ }^{3}$, S. O. CONDE $^{4}$, A. NADER FILHO ${ }^{5}$
}

\begin{abstract}
RESUMO
Com o objetivo de conhecer as características fenotípicas e genotípicas das estirpes de Staphylococcus aureus isoladas de queijo Minas artesanal, produzido na região de Araxá - MG, 30 amostras de uma determinada marca comercializada no município de Sacramento-MG foram analisadas bioquímica e molecularmente. Deste total, $100 \%$ estavam em desacordo com a Lei $\mathrm{n}^{\circ} 14.185$, que dispõe sobre o processo de produção de queijo Minas artesanal, devido à elevada contagem de estafilococos coagulase-positivos. Para a análise molecular, genotiparam-se 63 colônias oriundas das 30 amostras de queijo Minas artesanal. Todas as colônias foram caracterizadas bioquimicamente como estafilococos coagulase-positivos, e $56(88,8 \%)$ colônias foram positivas para a espécie $S$. aureus nas análises moleculares. Os resultados obtidos indicam a necessidade de adoção de medidas por parte das autoridades sanitárias, uma vez que tais queijos, por serem produzidos com leite cru, não pasteurizado, colocam em risco a saúde dos consumidores.
\end{abstract}

PALAVRAS-CHAVE: Estafilococos coagulase-positivos. PCR. Saúde pública.

\section{SUMMARY}

Thirty samples of a brand cheese commercialized in the municipality of Sacramento, MG, Brazil were analyzed for their biochemical and molecular traits to detect the phenotype and genotype of Staphylococcus aureus strains isolated from Minas artisanal cheese produced in the region of Araxá, MG, Brazil. All samples failed to comply with Law 14185 on the production process of Minas artisanal cheese, owing to high counts in coagulase-positive staphylococcus. Sixty-three colonies from 30 samples of Minas artisanal cheese were genotyped for molecular analysis. All colonies were biochemically detected as coagulase-positive staphylococcus, of which $56(88.8 \%)$ were positive for $S$. aureus in molecular analyses. Results reveal the need for urgent measures by health authorities since the above mentioned cheese, produced from non-pasteurized milk, put at risk consumers’ health.

KEY-WORDS: Coagulase-positive staphylococcus. PCR. Public health.

\footnotetext{
${ }^{1}$ Pesquisadora da Embrapa Caprinos e Ovinos, Sobral-CE. E-mail: viviane.souza@embrapa.br.

${ }^{2}$ Professora Adjunta de Doenças Infecciosas e Parasitárias. Departamento de Ciências Agrárias e Ambientais, Universidade Estadu al de Santa Cruz, Ilhéus-BA.

${ }^{3}$ Pesquisador Científico - APTA - SAA-SP - Pólo Regional Centro Oeste - Bauru-SP.

${ }^{4}$ Técnica de Laboratório da Faculdade de Medicina de Ribeirão Preto-SP - FMRP-USP.

${ }^{5}$ Professor titular do Departamento de Medicina Veterinária Preventiva da Faculdade de Ciências Agrárias e Veterinárias, Unesp Jaboticabal-SP.
} 


\section{INTRODUÇÃO}

Visando manter a tradição na produção de queijos, o governo de Minas Gerais, por meio do Instituto Mineiro de Agropecuária (IMA), regulamentou a produção de queijo Minas artesanal no referido Estado. Segundo a Lei $n^{\circ} 14.185$ (IMA, 2002), entende-se por queijo Minas artesanal o queijo produzido segundo a tradição histórica e cultural da região onde for produzido, tendo como matéria-prima leite integral de vaca, hígido, recém-ordenhado e cru, retirado e beneficiado na propriedade de origem, que apresente consistência firme, cor e sabor próprios, massa uniforme, isenta de corantes e conservantes, com ou sem olhaduras mecânicas.

O Programa Queijo Minas Artesanal promove a identidade dos queijos artesanais produzidos nas regiões de Araxá, Canastra, Cerrado, Serro, Campo das Vertentes e Triângulo Mineiro. O interessado em cadastrar-se como produtor de queijo Minas artesanal deve atender às especificações referentes a produção, equipamentos, higiene, controle de saúde dos trabalhadores e dos animais, entre outros, e seguir a regulamentação preconizada pelo Instituto Mineiro de Agropecuária, órgão responsável (IMA, 2002).

Considerando-se que esse tipo de queijo é produzido a partir de leite cru e não é submetido a tratamento térmico, o risco de ser veiculador de microorganismos patogênicos, como Staphylococcus aureus, constitui importante problema de Saúde pública.

O $S$. aureus é conhecido como um dos principais agentes causadores da mastite subclínica, causando danos à glândula mamária e comprometendo as características físico-químicas e microbiológicas do leite sem que o produtor perceba sua presença. Por se tratar de um micro-organismo patogênico que apresenta uma grande capacidade de adaptação a condições ambientais adversas, representa um importante agente de toxi-infecção alimentar. A presença de Staphylococcus nos alimentos é encarada como um indicador de deficiências de carácter higiênico no processo de obtenção do alimento e particularmente nas operações de manipulação (BORGES et al., 2008).

As limitações conferidas pelos métodos de cultivo levaram ao desenvolvimento de técnicas de reação em cadeia pela polimerase (Polymerase Chain Reaction - PCR), as quais permitem a detecção de micro-organismos mesmo em números reduzidos (FORSMAN et al., 1997; PHUEKTES et al., 2003), tornando-se uma opção promissora para uma rápida identificação bacteriana pela utilização de sequências de ácido desoxirribonucleico (DNA) espécieespecíficas.

Diante do exposto, idealizou-se o presente trabalho com a finalidade de avaliar a qualidade microbiológica de queijo Minas artesanal, produzido na microrregião de Araxá, em Minas Gerais, por meio da quantificação, identificação e confirmação genotípica de estirpes de $S$. aureus.
Durante o período de janeiro a julho de 2009, foram analisadas 30 amostras de queijo Minas artesanal da microrregião de Araxá, todas de uma única marca, devidamente registrada no Instituto Mineiro de Agropecuária, colhidas em diferentes pontos de venda no comércio varejista do município de Sacramento-MG.

A colheita das amostras foi realizada em dias diferentes, visando obter lotes distintos do produto. No momento da amostragem, foi realizada a anotação dos dados referentes à data de fabricação e ao prazo de validade dos queijos avaliados. As amostras foram transportadas em caixa de material isotérmico contendo gelo e levadas ao Laboratório de Análises Microbiológicas de Alimentos do Departamento de Medicina Veterinária Preventiva e Reprodução Animal, da Faculdade de Ciências Agrárias e Veterinárias, Universidade Estadual Paulista - FCAV, UNESP - Campus de Jaboticabal - SP.

De cada amostra, foi pesada assepticamente, e transferida para um saco plástico estéril, uma alíquota de $25 \mathrm{~g}$, sendo essa homogeneizada em aparelho Stomacher, com $225 \mathrm{~mL}$ de água peptonada $0,1 \%$, obtendo-se assim uma diluição inicial de $10^{-1}$. A partir dessa diluição, foram preparadas diluições decimais até $10^{-6}$, sendo utilizado o mesmo diluente. Das diluições $10^{-3}$ a $10^{-6}$ foram retiradas alíquotas de $0,1 \mathrm{~mL}$ e depositadas em placas de Petri contendo ágar de BairdParker. A seguir, com auxílio de um bastão em forma de "L" esterilizado, foi procedida à distribuição do inóculo por toda a superfície do meio, e as placas foram incubadas a $35^{\circ} \mathrm{C}$ por 24 a 48 horas. Após incubação, foram contadas as placas contendo de 20 a 200 colônias, separadamente, colônias negras, brilhantes, com zona de precipitação ao redor e circundadas ou não por halo claro, além das que se apresentavam somente negras e brilhantes. Os números de colônias contados foram multiplicados pelo fator 10 e, em seguida, pela recíproca da diluição correspondente à placa de contagem, obtendo-se assim o valor da contagem presuntiva de Staphylococcus spp. A seguir, de 3 a 5 colônias de cada tipo foram semeadas em tubos com ágar nutriente inclinado, os quais foram incubados a $35^{\circ} \mathrm{C}$ por 24 horas. Após, foram preparados esfregaços corados pelo método de Gram, e as culturas apresentadas em forma de cocos Gram-positivos, agrupadas em forma de cachos de uva, foram submetidas às provas de catalase, da coagulase livre e de produção de acetoína (VP) (Mac FADDIN, 1976). Para a extração do DNA bacteriano foi utilizado o Kit Invitek - Uniscience $\AA$, que contém o protocolo de extração de DNA para bactérias Gram-positivas. Posteriormente, a confirmação molecular dos isolados de $S$. aureus, para a identificação da espécie, foi feita a partir da amplificação de fragmentos de DNA cromossômico específico do $S$. aureus de acordo com o protocolo descrito por Martineau et al. (1998).

\section{RESULTADOS E DISCUSSÃO}

Das 30 amostras analisadas, 28 (93,3\%) apresentaram-se fora dos padrões estabelecidos pela Lei $\mathrm{n}^{\circ} 14.185$, de 31 de janeiro de 2002, que dispõe 
sobre o processo de produção de queijo Minas artesanal no Estado de Minas Gerais (IMA, 2002).

As contagens de estafilococos coagulasepositivos obtidas nas amostras do presente estudo variaram de 3,0 × $10^{2}$ a 2,0 × $10^{7}$ Unidades Formadoras de Colônias (UFC. $\mathrm{g}^{-1}$ ), com média aritmética de 7,2 $\mathrm{x}$ $10^{5}$ UFC.g $^{-1}$.

Araujo (2004), ao analisar 37 amostras de queijo Minas artesanal da região de Araxá - MG, obteve $33(89,2 \%)$ amostras positivas para estafilococos coagulase-positivos. A alta contagem de estafilococos coagulase-positivos, possivelmente $S$. aureus, é comum em trabalhos que analisam queijos produzidos a partir de leite cru no Brasil, como o queijo Minas artesanal (ALMEIDA et al., 2012; KOMATSU et al., 2010; BRANT et al., 2007; LOGUERCIO \& ALEIXO, 2001).

Para a análise molecular, genotiparam-se em média duas colônias de uma mesma amostra, totalizando 63 colônias oriundas das 30 amostras de queijo Minas artesanal, sendo todas caracterizadas bioquimicamente como Staphylococcus coagulasepositivos, e em $56(88,8 \%)$ foi amplificado o fragmento de DNA cromossômico específico da espécie de $S$. aureus (Figura 1).

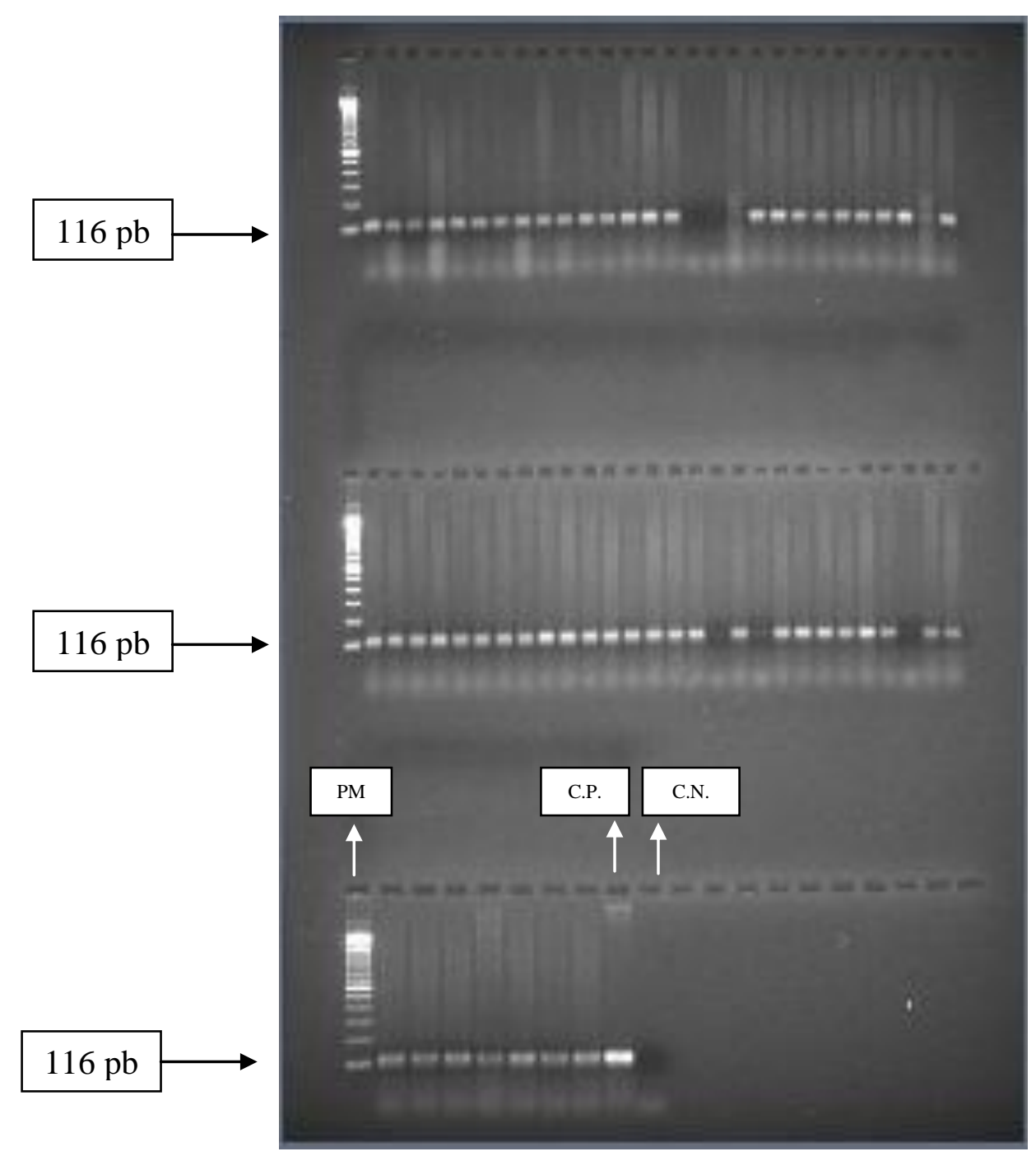

Figura 1 - Amostras submetidas à análise molecular para confirmação da espécie S. aureus.

PM: Marcador de Peso Molecular Ladder 100 (Invitrogen ${ }^{\circledR}$ )

C.P.: Controle positivo (utilização de DNA da ATCC 23.235)

C.N.: Controle negativo (utilização de água mili-Q estéril e filtrada)

Medeiros et al. (2013) realizaram um monitoramento epidemiológico molecular de estirpes de $S$. aureus potencialmente toxigênicas isoladas no processo de produção do queijo Minas frescal em microusina do Estado de São Paulo, no período de junho de 2008 a julho de 2009, e verificaram que, das
74 estirpes de estafilococos coagulase-positivos isoladas, $41(55,4 \%)$ amostras foram confirmadas como sendo Staphylococcus aureus. Ao realizar a técnica de PCR, a presença de Staphylococcus aureus foi confirmada em $28(93,3 \%)$ amostras de queijo Minas artesanal analisadas. 
A alta ocorrência de $S$. aureus nas amostras do presente estudo pode estar relacionada com a presença de mastite bovina no rebanho leiteiro, porém fatores como obtenção inadequada de leite e hábitos higiênicos insatisfatórios podem contribuir para o aumento na ocorrência desse micro-organismo em queijos artesanais (PINTO, 2004). S. aureus é classificado entre os patógenos contagiosos, uma vez que a exposição de quartos mamários não infectados é geralmente limitada ao processo de ordenha (FOX \& GAY, 1993; SMITH \& HOGAN, 1993). A principal fonte de infecção são animais com quartos mamários infectados por $S$. aureus, além da pele do úbere e dos tetos contaminados, enquanto os bocais da ordenhadeira são considerados a principal via de transmissão da infecção (MYLLYS et al., 1997).

As infecções intramamárias causadas por $S$. aureus apresentam implicações importantes em Saúde pública, tendo em vista que $S$. aureus enterotoxigênicos podem ser excretados no leite e contaminar produtos destinados aos consumidores (FAGUNDES \& OLIVEIRA, 2004).

\section{CONCLUSÃO}

As análises efetuadas neste estudo evidenciaram que $93,3 \%$ das amostras de queijo Minas artesanal analisadas estavam em condições higiênico-sanitárias insatisfatórias, por apresentarem S. aureus acima dos padrões legais vigentes.

\section{AGRADECIMENTOS}

À Fundação de Amparo à Pesquisa do Estado de São Paulo (FAPESP) pelo financiamento do projeto e ao Conselho Nacional de Desenvolvimento e Pesquisa (CNPq) pela bolsa concedida durante a execução da pesquisa.

\section{REFERÊNCIAS}

ALMEIDA, A. C.; DINIS, T. T.; DE SOUZA, M. R.; PINTO, M. S.; DE SOUZA, R. M; SILVA, N. O.; QUEIROZ, M. R. A. Caracterização da produção de queijo artesanal na região de Montes Claros, Norte de Minas Gerais. Acta Veterinaria Brasilica, v.6, n.4, p.312-320, 2012.

ARAUJO, R. A. B. M. Diagnóstico socioeconômico, cultural e avaliação dos parâmetros físico-químicos e microbiológicos do queijo minas artesanal da região de Araxá. Viçosa - MG, 2004. 121 f. Dissertação (Mestrado em Ciências e Tecnologias de Alimentos) - Universidade Federal de Viçosa, Viçosa - MG. Disponível em: http://alexandria.cpd.ufv.br:8000/teses/ciencia\%20e\%20te cnologia\%20de\%20alimentos/2004/188343f.pdf. 2004.

BORGES, M. F.; ARCURI, E. F.; PEREIRA, J. L.; FEITOSA, T.; KUAYE, A. Y. Staphylococcus enterotoxigênicos em leite e produtos lácteos, suas enterotoxinas e genes associados: revisão. Boletim do Centro de Pesquisa de Processamento de Alimentos, v.34, n.1, p.70-86, 2008.
BRANT, L. M. F.; FONSECA, L. M.; SILVA, M. C. C. Avaliação da qualidade microbiológica do queijode-minas artesanal do Serro-MG. Arquivo Brasileiro de Medicina Veterinária e Zootecnia, v.59, n.6, p.15701574, 2007.

FAGUNDES, H.; OLIVEIRA, C. A. F. Infecções intramamárias causadas por Staphylococcus aureus e suas implicações em saúde pública. Ciência Rural, v.34, n.4, p.1315-1320, 2004.

FORSMAN, P.; TILSALA-TIMISJARVI, A.; ALATOSSAVA, T. Identification of staphylococcal and streptococcal causes of bovine mastitis using 16S23S rRNA spacer regions. Microbiology, v.143, n.11, p.3491-3500, 1997.

FOX, L.; GAY, J. Contagious Mastitis. In: E. Hunt, K. L. Anderson (eds.): The Veterinary Clinics of North America: Food Animal Practice. Philadelphia: W.B. Saunders Company; 1993. p.475-487.

IMA - INSTITUTO MINEIRO DE AGROPECUÁRIA. Lei no 14.185 de 31 de janeiro de 2002. Dispõe sobre o processo de produção de queijo Minas Artesanal e dá outras providências. Disponível em:

http://imanet.ima.mg.gov.br/nova/gce/outros_documen tos/42645.pdf. Acesso em: 22/08/2014.

KOMATSU, R. S.; RODRIGUES, M. A. M.; LORENO, W. B. N.; SANTOS, K. A. Ocorrência de Staphylococcus coagulase positiva em queijos minas frescal produzidos em Uberlândia-MG. Bioscience Journal, v.26, n.2, p.316-321, 2010.

LOGUERCIO, A. P.; ALEIXO, J. A. G. Microbiologia de queijo tipo Minas Frescal produzido artesanalmente. Ciência Rural [online], v.31, n.6, p.1063-1067, 2001.

Mac FADDIN J.F. Biochemical tests for identification of medical bacteria. Baltimore: The Williams \& Wilkins. 1976; 312 p.

MARTINEAU, F.; PICARD, F. J.; ROY, P. H; OUELLETTE, M; BERGERON, M. G. Speciesspecific and ubiquitous-DNA-based assays for rapid identification of Staphylococcus aureus. Journal of Clinical Microbiology, v.36, n.3, p.618-623, 1998.

MEDEIROS, M. I. M.; NADER FILHO, A.; SOUZA, V.; MELO, P. C.; FERREIRA, L. M.; CANALEJO, L. M. M. Epidemiologia molecular aplicada ao monitoramento de estirpes de Staphylococcus aureus na produção de Queijo Minas Frescal. Ciência Animal Brasileira, v.14, n.1, p.98-105, 2013.

MYLLYS, V.; RIDELL, J.; BJORKROTH, I.; PYORALA, S. H. K. Persistence in bovine mastitis of Staphylococcus aureus clones as assessed by random amplified polymorphic DNA analysis, ribotyping and biotyping. Veterinary Microbiology, v.57, n.1-2, p.245$251,1997$. 
PINTO, M. S. Diagnóstico Sócio-econômico cultural e Avaliação Microbiológica do Queijo Minas Artesanal do Serro - MG. Viçosa - MG, 2004. 104 f. Dissertação (Mestrado em Ciências e Tecnologias de Alimentos) Universidade Federal de Viçosa, Viçosa - MG. Disponível em: http://alexandria.cpd.ufv.br:8000/teses/ciencia\%20e\%20te cnologia\%20de\%20alimentos/2004/183060f.pdf. 2004.

PHUEKTES, P.; MANSELL, P.; BROWNING, G. F. Multiplex polymerase chain reaction as a mastitis screening test for Staphylococcus aureus, Streptococcus agalactiae, Streptococcus dysgalactiae and Streptococcus uberis in bulk milk samples. Journal of Dairy Research, v.70, n.2, p.149-155, 2003.
SMITH, K; HOGAN, J. Environmental Mastitis. In: E. Hunt, K. L. Anderson (eds.): The Veterinary Clinics of North America: Food Animal Practice. Philadelphia: W.B. Saunders Company; 1993. p.489-498. 